\title{
A New Species of the Genus Eosentomon (Insecta: Protura: Eosentomidae) from Rishiri Island, Hokkaido, Northern Japan
}

\author{
Osami Nakamura \\ Saitama Museum of Natural History, Nagatoro 1417, Saitama, 369-1305 Japan \\ E-mail: osami@nakamura.email.ne.jp
}

(Received 7 July 2003; Accepted 17 May 2004)

\begin{abstract}
A new species of the proturan genus Eosentomon, E. rishir, is described from Rishiri Island, Hokkaido, northern Japan. The present species is characterized by the position and/or shape of sensilla $c^{\prime}$ and $b$ on the foretarsus, the absence of A5 on abdominal tergites IV-VII, and the position and shape of P1a on tergites II-VII. An updated key to the Japanese species of Eosentomon is presented.
\end{abstract}

Key Words: Protura, Eosentomon, new species, Japan, key.

\section{Introduction}

Eosentomon Berlese, 1908, the largest genus in Protura, now comprises more than 260 species (Szeptycki 2003) and is common in most areas of the world. Sixteen species of the genus have so far been recorded from Japan (Imadaté 1995).

In a faunal survey of soil animals on Rishiri Island, an unusual species of Eosentomon was collected, which has short and capitulate accessory setae P1a on abdominal tergites I-VII and lacks the anterior setae A5 on abdominal tergites IV-VII. Among congeneric species, these two setal features are very rare. Moreover, the posterior setae P5 are displaced anteriorly on tergites IV-VII. For these reasons, the specimens from Rishiri Island are described as a new species of Eosentomon, and an updated key to the Japanese congeners is provided as well.

\section{Material and Methods}

Proturans were collected from litter and soil of a coniferous forest on Rishiri Island, Hokkaido, in Tullgren funnels. All the extracted proturans were individually mounted in polyvinyl-lactophenol medium. The slides were dried for three days in an oven at $60^{\circ} \mathrm{C}$.

The type specimens of the present new species are deposited in the National Science Museum, Tokyo (NSMT).

The indices and terminology of body chaetotaxy are after Imadate (1974), and the terminology of head and hind tarsus chaetotaxy and shape of setae, sensilla, and microsetae are after Bernard (1990). 


\section{Taxonomy}

Eosentomon rishir sp. nov.

(Figs 1-17)

Eosentomon sp. Ri: Nakamura 2003; 67.

Diagnosis. Belonging to wheeleri-group of Tuxen (1964). Sensilla posterior to pseudoculus distinct. Foretarsal sensilla $b, t 2$, and $b^{\prime} 2$ spatulate, $b^{\prime} 1$ and $c^{\prime}$ broad, and $c^{\prime}$ posterior to base of $\alpha 6$. P1a on thoracic tergites and abdominal tergites I-VII short, capitulate, and situated at same level with P1 and P2; A5 absent on tergites IV-VII; P2a on tergite VIII linear.

Description. Body length. $760-1138 \mu \mathrm{m}$ (1138 $\mu \mathrm{m}$ in holotype in expanded condition).

Head. 106-117 $\mu \mathrm{m}$ long, $76-83 \mu \mathrm{m}$ wide. Anterior additional setae absent; posterior additional setae ( $p a)$, seta $m 4$, and anterior and posterior sensilla ( $a s$ and $p s$ ) present; subposterior setae $(s p)$ about 1.5 times longer than posterior setae $(p)$ (Fig. 1). Clypeal apodemes distinct (Fig. 2). Labral setae (b) present; rostral setae ( $r s$ ) slightly inflated basally, shorter than subrostral setae (s) (Fig. 2). Maxillary palpus with two sensilla, dorsal sensillum $(d) 7.9-8.6 \mu \mathrm{m}$ long, longer than lateral sensillum (l) $6.3-6.6 \mu \mathrm{m}$ in length (Fig. 3). Digits of galea small, blunt, and subequal in length and shape to each other (Fig. 4). Mandible with two teeth. Pseudoculus almost circular with no inner structure (Fig. 5), about $10 \mu \mathrm{m}$ wide, $\mathrm{PR}=11.2-11.5$. Sensilla posterior to pseudoculus distinct, $2-3 \mu \mathrm{m}$ long (Fig. 5).

Legs. Foretarsus length (Figs 6, 7) $76-83 \mu \mathrm{m}$, claw $18-20 \mu \mathrm{m}, \mathrm{TR}=4.0-4.4$, empodium slightly shorter than claw, $16-17 \mu \mathrm{m}, \mathrm{EU}=0.83-0.90$, S-shaped seta subequal to or slightly longer than claw, 18-22 $\mu \mathrm{m}$. Dorsal sensillum $t 1$ situated halfway between bases of $\alpha 3$ and $\alpha 3^{\prime}$, BS=0.93-0.99; $t 2$ spatulate; $t 3$ thin. Exterior sensillum $a$ normal; $b$ rounded spatulate; $c$ linear; $d$ relatively long and surpassing base of $\alpha 5 ; e$ normal with long, spatulate dilatation; $f 1$ thin and relatively long; $f 2$ thin and small; $g$ normal with long, spatulate dilatation. Interior sensillum $a^{\prime}$ thin; $b^{\prime} 1$ broad and nearer to base of $\delta 3^{\prime}$ than to that of $\delta 4^{\prime} ; b^{\prime} 2$ weakly spatulate and narrower than $t 2 ; c^{\prime}$ broad and posterior to base of $\alpha 6$, situated on line between bases of $\alpha 6$ and $\delta 4^{\prime}$. Row of tubercles present between bases of $\delta 3$ and $b$. Pores present just proximal to $\alpha 3^{\prime}$ and y. Middle tarsus $36-43 \mu \mathrm{m}$ long, claw $12-14 \mu \mathrm{m}$; hind tarsus 49-54 $\mu \mathrm{m}$ long, claw 13-14 $\mu \mathrm{m}$; empodia of both tarsi very short. On hind tarsus, setae D2 and D5 spine-like, but D2 slightly more slender than D5 (Fig. 8).

Body. Tracheal camerae relatively long, distally contracted (Fig. 13). Chaetotaxy as in Table 1 and Figs 9-12. On thoracic tergites II and III, P1a sensillum-like and linear, situated at same level with P1 and P2, nearer to P2 than to P1; P2a setalike and situated at same level with P2 and P3 (Fig. 9). On thoracic tergite III, microchaetae P5a and P5a' present (Fig. 9).

Abdominal tergite I with microchaetae P3a and P3a' (Fig. 9); tergites II and III with five pairs of anterior setae, A1 to A5 (Fig. 10); tergites IV-VI with three pairs, A1, A2, and A4; tergite VII with one pair, A4 (Fig. 11); and tergites IX-XI with four pairs of setae. On tergites II-VII, P2 situated at same level with P1, anteriorly to row of P3 and P4 (Fig. 11). On tergites IV-VII, P5 displaced anteriorly and situated at almost same level with A4 (Fig. 11). On tergites I-VII, P1a situated in same row 

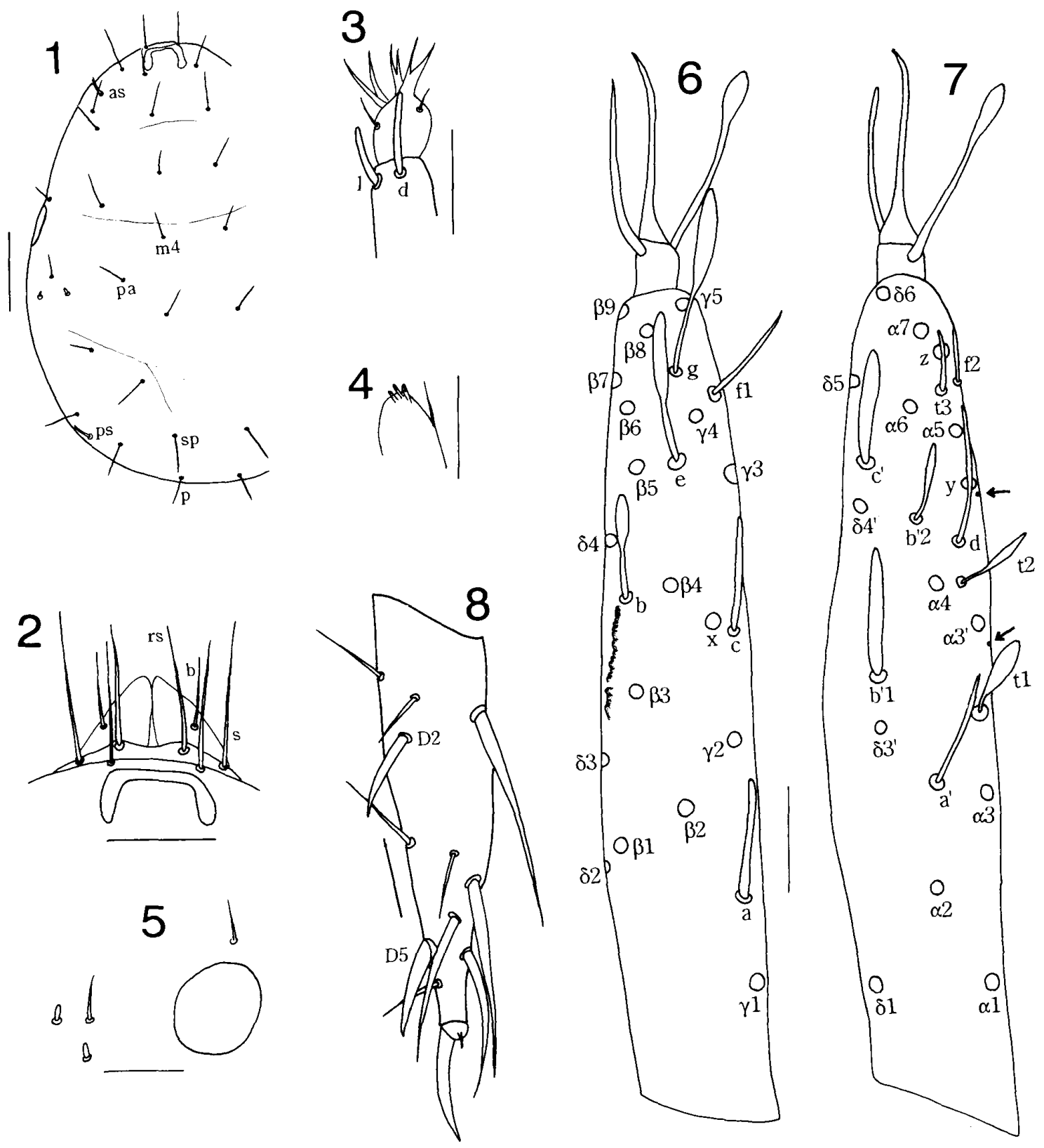

Figs 1-8. Eosentomon rishir sp. nov. 1, Dorsal view of head, left side; 2, labrum and rostral region; 3 , maxillary palpus; 4 , galea; 5 , pseudoculus; 6 , exterior view of foretarsus; 7 , interior view of foretarsus, arrows indicate integumental pores; 8, hind tarsus. 1-4, 6-8, Holotype, female; 5 , paratype, female. Scale bars: $20 \mu \mathrm{m}$ for Fig. 1; $10 \mu \mathrm{m}$ for Figs 2-8.

with P1 and P2, sensillum-like and capitulate, shorter than P1 (Fig. 12), but P1a on tergite III often delicate like P2a; P2a situated somewhat posteriorly to P2 and P3, delicate and longer than P1 (Figs 10,11). On tergite VIII, P1a' with slight basal dilatation; P2a linear (Fig. 12). Sternite VIII with single row of seven posterior setae. Openings of dermal glands present between tergites IX and X as well as between tergites X and XI; tergite XII with two central pores. Central lobe of praecosta trapezoidal, not incised (Fig. 14). Laterostigmata II-IV relatively large with weak 

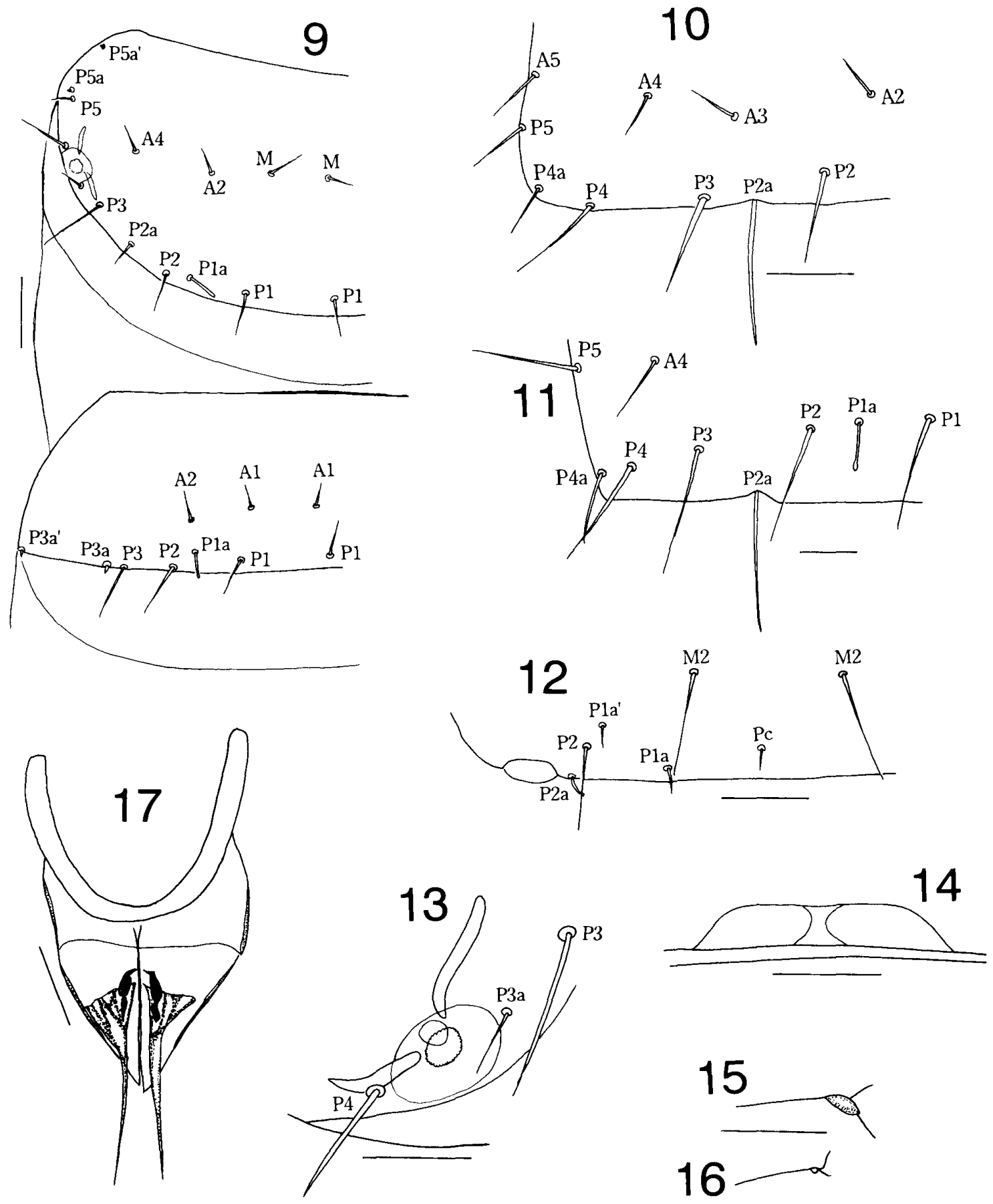

Figs 9-17. Eosentomon rishir sp. nov., holotype, female. 9, Thoracic tergite III and abdominal tergite I, left half; 10, abdominal tergite III, left half; 11, abdominal tergite VII, left half; 12, abdominal tergite VIII, left half; 13, tracheal camerae on thorax III; 14, central lobe on abdominal tergite VI; 15, laterostigma IV; 16, laterostigma V; 17, squama genitalis. Scale bars: $20 \mu \mathrm{m}$ for Fig. 9; $10 \mu \mathrm{m}$ for Figs 10-17. 
Table 1. Chaetotaxy of Eosentomon rishir sp. nov.

\begin{tabular}{|c|c|c|c|c|}
\hline & \multicolumn{2}{|r|}{ Dorsal } & \multicolumn{2}{|r|}{ Ventral } \\
\hline & Formula & Composition of setae & Formula & Composition of setae \\
\hline \multicolumn{5}{|l|}{ Thorax } \\
\hline \multirow[t]{2}{*}{ I } & 4 & 1,2 & $6-2$ & $\mathrm{~A} 1,2,3, \mathrm{M}$ \\
\hline & & & 6 & $\mathrm{P} 1,2,3$ \\
\hline \multirow[t]{2}{*}{ II } & 6 & $\mathrm{~A} 2,4, \mathrm{M}$ & $6-2$ & $\mathrm{~A} 1,2,3, \mathrm{M}$ \\
\hline & 16 & $\mathrm{P} 1,1 \mathrm{a}, 2,2 \mathrm{a}, 3,3 \mathrm{a}, 4,5$ & 6 & $\mathrm{P} 1,2,3$ \\
\hline \multirow[t]{2}{*}{ III } & 6 & $\mathrm{~A} 2,4, \mathrm{M}$ & $6-4$ & $\mathrm{~A} 1,2,3, \mathrm{M} 1,2$ \\
\hline & 20 & $\mathrm{P} 1,1 \mathrm{a}, 2,2 \mathrm{a}, 3,3 \mathrm{a}, 4,5,5 \mathrm{a}, 5 \mathrm{a}^{\prime}$ & 8 & $\mathrm{P} 1,2,2 \mathrm{a}, 3$ \\
\hline \multicolumn{5}{|c|}{ Abdomen } \\
\hline \multirow[t]{2}{*}{ I } & 4 & $\mathrm{~A} 1,2$ & 4 & $\mathrm{~A} 1,2$ \\
\hline & 12 & $\mathrm{P} 1,1 \mathrm{a}, 2,3,3 \mathrm{a}, 3 \mathrm{a}^{\prime}$ & 4 & $\mathrm{P} 1,2$ \\
\hline \multirow[t]{2}{*}{ II-III } & 10 & $\mathrm{~A} 1,2,3,4,5$ & 6 & $\mathrm{~A} 1,2,3$ \\
\hline & 16 & $\mathrm{P} 1,1 \mathrm{a}, 2,2 \mathrm{a}, 3,4,4 \mathrm{a}, 5$ & 4 & $\mathrm{P} 1,2$ \\
\hline \multirow[t]{2}{*}{ IV-VI } & 6 & $\mathrm{~A} 1,2,4$ & 6 & $\mathrm{~A} 1,2,3$ \\
\hline & 16 & $\mathrm{P} 1,1 \mathrm{a}, 2,2 \mathrm{a}, 3,4,4 \mathrm{a}, 5$ & 10 & $\mathrm{P} 1,2,2 \mathrm{a}, 2 \mathrm{a}^{\prime}, 3$ \\
\hline \multirow[t]{2}{*}{ VII } & 2 & $\mathrm{~A} 4$ & 6 & $\mathrm{~A} 1,2,3$ \\
\hline & 16 & $\mathrm{P} 1,1 \mathrm{a}, 2,2 \mathrm{a}, 3,4,4 \mathrm{a}, 5$ & 10 & $\mathrm{P} 1,2,2 \mathrm{a}, 2 \mathrm{a}^{\prime}, 3$ \\
\hline \multirow[t]{2}{*}{ VIII } & 6 & $\mathrm{M} 2,4,5$ & 0 & \\
\hline & 9 & $\mathrm{Pc}, 1 \mathrm{a}, 1 \mathrm{a}^{\prime}, 2,2 \mathrm{a}$ & 7 & Pc, $1,1 \mathrm{a}, 2$ \\
\hline IX-X & 8 & $1,2,3,4$ & 6 & $1,1 \mathrm{a}, 2$ \\
\hline $\mathrm{XI}$ & 8 & $1,2,3,4$ & 8 & $1,2,3,4$ \\
\hline XII & 9 & & 12 & \\
\hline
\end{tabular}

reticulation (Fig. 15); those of tergites V and VI small, with no reticulation (Fig. 16). Serrate lines present on sternite XII. On female squama genitalis (Fig. 17), caput processus distally contracted and curved towards median edge of stylus, corpus processus developed, filum processus of medium length.

Type series. Holotype: female, Kutsugata, Rishiri-cho, Rishiri Is., Hokkaido, $45^{\circ} 10^{\prime} 48^{\prime \prime} \mathrm{N}, 141^{\circ} 10^{\prime} 38^{\prime \prime} \mathrm{E}, 200 \mathrm{~m}$ alt., evergreen coniferous forest dominated by Abies sachalinensis (Fr. Schm.) Masters and Picea jezoensis (Sieb. et Zucc.) Carrière, 21VI-2000, T. Maehara leg. Paratypes: two males and three females, same data as for holotype; one female, Kutsugata, Rishiri-cho, Rishiri Is., Hokkaido, $45^{\circ} 10^{\prime} 44^{\prime \prime} \mathrm{N}$, $141^{\circ} 11^{\prime} 38^{\prime \prime} \mathrm{E}, 400 \mathrm{~m}$ alt., evergreen coniferous forest dominated by $A$. sachalinensis and $P$. jezoensis with Sasa sp. as ground cover, 20-VI-2000, T. Maehara leg.

The holotype (NSMT-Ap 364) and six paratypes (NSMT-Ap 365-370) are deposited in the collection of the Natural Science Museum, Tokyo.

Etymology. The specific epithet, a noun in apposition, is derived from an Ainu word, rishir, meaning a height or an island with a high mountain. It is the origin of the name of Rishiri Island.

Remarks. The present new species is characterized by the position of foretarsal sensillum $c^{\prime}$, which is situated proximally to the base of $\alpha 6$, and the absence of A5 on abdominal tergites IV-VII. It is therefore closely similar to E. kimum Imadaté, 1964 and E. nupri Nakamura, 1983 from Japan (Hokkaido) (cf. Imadaté 1964; Nakamura 1983), but it is distinguished from these two species by the shapes of P1a on abdominal tergites II-VII (delicate and/or linear in E. kimum and E. nupri) and of foretarsal sensillum $b$ (thin in E. kimum and E. nupri). Eosentomon rishir is sep- 
arated from $E$. kimum also by the shape of foretarsal sensilla $b^{\prime} 1$ and $c^{\prime}$ (thin in $E$. kimum), and from E. nupri by the shape of the female squama genitalis (rods in corpus processus united to form a V-shape in $E$. nupri) and the chaetotaxy of the abdominal tergites VI (A2 absent in $E$. nupri).

The absence of P5 on abdominal tergites IV (or V)-VII is observed also in $E$. depilatum Bonet, 1950 from Mexico, E. kamenickiense Rusek, 1974 from the Czech Republic (Bohemia), E. microphthalmus Tuxen, 1978 and E. subnudum Tuxen, 1978 from the Seychelles, E. noonadanae Tuxen and Imadate, 1975 from the Bismarck Archipelago, and E. pratense Rusek, 1973 from the Czech Republic (Moravia), Poland, and Yugoslavia (Rusek 1973, 1974; Szeptycki 1985; Tuxen 1964, 1978; Tuxen and Imadate 1975). The present new species is easily distinguishable from these by the shape and/or position of P1a on abdominal tergites II-VII (not capitulate and posterior to $\mathrm{P} 1-2$ in these species), the position of foretarsal sensillum $c^{\prime}$ (anterior to the base of $\alpha 6$ in these species), the shape of $b, t 2$, and $b^{\prime} 2$ (not spatulate in these species), and the absence of $b^{\prime} 1$ (present in five of these species aside from $E$. $m i$ crophthalmus).

This new species resembles E. stumppi Rusek, 1988 from Germany in having capitulate P1a on abdominal tergite VII, but is easily distinguished from the latter (cf. Rusek 1988) in the shape and position of P1a on II-VI (longer than P1 and situated at the posterior margin in $E$. stumppi), the presence of A5 on IV-VII, the position and/or shape of foretarsal sensilla $c^{\prime}, b, t 2$, and $b^{\prime} 2$, and the absence of $b^{\prime} 1$.

Some chaetotaxial variation was observed within the new species. P5a and $\mathrm{P}^{2} \mathrm{a}^{\prime}$ on thoracic tergite II were present in one female. On abdominal tergites IV and VI of one female, one P1a was delicate and situated somewhat posteriorly to P1 and $\mathrm{P} 2$.

Posterior setae P5 on abdominal tergites IV-VII were displaced anteriorly and situated at almost the same level with A4. This character state was observed in $E$. nupri as well (Nakamura 1983). Both species lack A5 on those tergites. Although $E$. kimum also lacks A5 on those tergites, the position of P5 was not described in either Imadaté's (1964) original description or his monograph (Imadaté 1974). It is regrettable that the holotype (NSMT-Ap 4) of E. kimum was not in good condition and the position of P5 on IV-VII could not be observed. Therefore, I examined two other males of this species (NSMT-Ap 121, Nishi-shibetsu, Shibetsu-shi, Hokkaido, 3-IX-1969, identified by the late Dr. Imadaté), and found that they had P5 of these tergites in the same position as E. rishir and E. nupri do.

\section{Key to the Japanese species of Eosentomon}

1. Empodium of hind tarsus long, exceeding $1 / 2$ of claw length

E. udagawai Imadaté, 1961

- Empodium of hind tarsus normal, shorter than $1 / 5$ of claw length .................... 2

2. Pseudoculus with a few groups of minute globules .......................................... 3

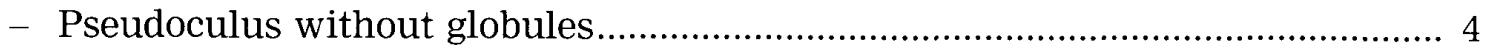

3. Foretarsal sensillum $b^{\prime} 1$ absent .............................................. toi Imadaté, 1964

- Foretarsal sensillum $b^{\prime} 1$ present.......................................... tokui Imadaté, 1974

4. Foretarsal sensillum $b^{\prime} 1$ absent ....................................................................... 5

- Foretarsal sensillum $b^{\prime} 1$ present .................................................................... 7

5. Foretarsal sensillum $t 1$ nearer to $\alpha 3^{\prime}$ than to $\alpha 3$; P1a on abdominal tergite VII level with P1-2 ................................................... k. kumei Imadaté and Yosii, 1959 
- Foretarsal sensillum $t 1$ nearer to $\alpha 3$ than to $\alpha 3^{\prime}$; P1a on abdominal tergite VII posterior to P1-2

6. Tergite $\mathrm{V}$ with four pairs of anterior setae (A1, A2, A4, and A5); six setae on sternites IX-X E. topochi Imadaté, 1964

- Tergite V with five pairs of anterior setae (A1-5); four setae on sternites IX-X.... E. yezoense Nakamura, 1983

7. A5 absent on abdominal tergites IV-VI; foretarsal sensillum $b^{\prime} 1$ nearer to $\delta 3^{\prime}$ than to $\delta 4^{\prime}$

- A5 present on abdominal tergites IV-VI; foretarsal sensillum $b^{\prime} 1$ halfway between $\delta 3^{\prime}$ and $\delta 4^{\prime}$

8. Foretarsal sensilla $b^{\prime} 1$ and $c^{\prime}$ thin; P1a on tergites II-VI long and posterior to P1-2 E. kimum Imadaté, 1964

- Foretarsal sensilla $b^{\prime} 1$ and $c^{\prime}$ thick; P1a on tergites II-VI short and level with $\mathrm{P} 1-2$

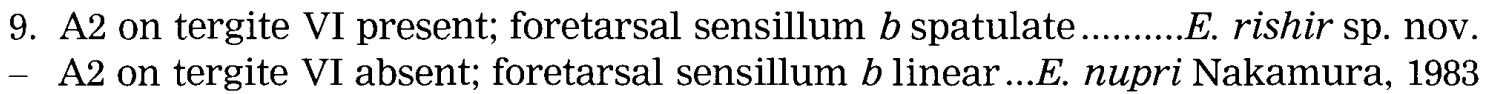

10. P1a on abdominal tergite VII level with P1-2...E. sakura Imadaté and Yosii, 1959

- P1a on abdominal tergite VII posterior to P1-2.

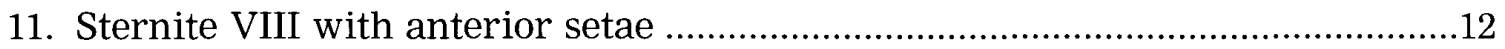

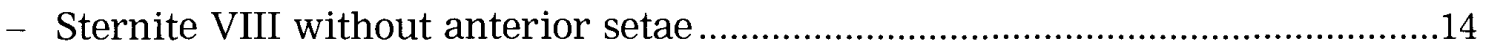

12. Tergite VII with four pairs of anterior setae (A1, A2, A4, and A5).

E. konsenense Imadaté, 1994

- Tergite VII with two pairs of anterior setae (A4 and A5)

13. Foretarsal sensillum $t 1$ nearer to $\alpha 3^{\prime}$ than to $\alpha 3 ; a^{\prime}$ level with $\alpha 3 \ldots$

E. asahi Imadaté, 1961

- Foretarsal sensillum $t 1$ nearer to $\alpha 3$ than to $\alpha 3^{\prime} ; a^{\prime}$ level with $t 1$.

E. juni Imadaté, 1994

14. Sternite VIII with posterior central seta (Pc)

- Sternite VIII without posterior central seta.

15. Foretarsal sensillum $t 1$ nearer to $\alpha 3$ than to $\alpha 3^{\prime}$; abdominal tergites V-VI with three pairs of anterior setae (A1, A4, and A5). E. tokiokai Imadaté, 1964

- Foretarsal sensillum $t 1$ between $\alpha 3$ and $\alpha 3^{\prime}$; abdominal tergites V-VI with two pairs of anterior setae (A4 and A5) E. dounanense Imadaté, 1994

16. Foretarsal sensillum $t 1$ nearer to $\alpha 3$ than to $\alpha 3^{\prime}$; abdominal tergites VI and VII with two pairs (A4 and A5) and one pair (A5) of anterior setae, respectively

E. pacificum Imadaté and Yosii, 1959

- Foretarsal sensillum $t 1$ nearer to $\alpha 3^{\prime}$ than to $\alpha 3$; abdominal tergites VI and VII with four pairs (A1, A2, A4, and A5) and two pairs (A4 and A5) of anterior setae, respectively E. asakawaense Imadaté, 1961

\section{Acknowledgements}

I am indebted to Dr. H. Ono, National Science Museum, Tokyo, for arranging the loan of the specimens of E. kimum, Drs. H. Tamura and A. Szeptycki for reading through the manuscript and giving valuable advice, and Dr. J. Rusek for his kind response to my inquiry. I sincerely thank anonymous reviewers for reading the manuscript carefully, and Mr. K. Furuno and Mr. T. Maehara for their cooper- 
ation in collecting the specimens. The materials used here were all collected with the permission (permit no. 408) of the Ministry of the Environment, Japan.

\section{References}

Bernard, E. C. 1990. New species, clarifications, and changes in status within Eosentomon Berlese (Hexapoda: Protura: Eosentomidae) from the United States. Proceedings of the Biological Society of Washington 103: 861-890.

Imadaté, G. 1964. Taxonomic arrangement of Japanese Protura (I). Bulletin of the National Science Museum, Tokyo 7: 263-293.

Imadaté, G. 1974. Fauna Japonica. Protura (Insecta). Keigaku Publishing, Tokyo, 351 pp.

Imadate, G. 1995. Contributions towards a revision of the proturan fauna of Japan. (X) Collecting data of eosentomid species in the Japanese Islands. Bulletin of the Department of General Education, Tokyo Medical and Dental University (25): 1-37.

Nakamura, O. 1983. Eosentomon nupri sp. nov. from Hokkaido (Protura, Eosentomidae). Kontyû, Tokyo 51: 596-600.

Nakamura, O. 2003. [Protura.] Pp. 66-67. In: Maehara, T., Hagiwara, Y., Ishii, K., Ito, R., Kurozumi, T., Sakayori, H., Suganami, Y., Tamura, H., Chinone, S., Nakamura, O., Naomi, S., Nunomura, N., Hagino, Y., Miyata, T. and Ishibashi, S. Soil animals from Rishiri Island, Northern Hokkaido. Rishiri Studies (22): 55-72. [In Japanese]

Rusek, J. 1973. Eosentomon pratensis sp. n. (Protura) aus Süd-Mähren. Acta Entomologica Bohemoslovaca 70: 55-59.

Rusek, J. 1974. Eosentomon kamenickiense sp. n. (Protura) aus Ost-Böhmen. Acta Entomologica Bohemoslovaca 71: 342-345.

Rusek, J. 1988. New Eosentomon and Acerentulus species (Protura) from Federal Republic Germany. Věstník Československé Společnosti Zoologické 52: 217-237.

Szeptycki, A. 1985. Polish Protura. II. Eosentomon delicatum Gisin, 1945, and related species. Polskie Pismo Entomologiczne 55: 139-186.

Szeptycki, A. 2003. August 7. Check list of the World Protura. 〈http://www.isez.pan. krakow.pl/catalogues/protura_main.htm). [Accessed 20 September 2003]

Tuxen, S. L. 1964. The Protura. A Revision of the Species of the World with Keys for Determination. Hermann, Paris, $360 \mathrm{pp}$.

Tuxen, S. L. 1978. The Protura (Insecta) of the Seychelles. Entomologica Scandinavica 9: 251-263.

Tuxen, S. L. and Imadaté, G. 1975. The Protura of the Bismarck Archipelago and Solomon Islands. Bulletin of the British Museum (Natural History), Entomology 31: 333-375. 